\title{
The Influence of Selected PNF Patterns on Kinaesthetic Force Differentiation Ability in Young Football Players
}

\author{
Paweł Ryngier ${ }^{1}$ \\ ${ }^{1}$ Faculty of Physiotherapy, Academy of Physical Education in Katowice \\ Correspondence to: Paweł Ryngier, \\ Faculty of Physiotherapy, Academy of Physical Education in Katowice, Mikołowska 72A, 40-065 Katowice, Poland, \\ p.ryngier@awf.katowice.pl \\ DOI: https://doi.org/10.5114/phr.2021.104598
}

Received: 04.01.2021 Reviewed: 15.01.2021 Accepted: 22.01.2021

\begin{abstract}
Background: The proprioceptive neuromuscular facilitation (PNF) method provides a full range of therapeutic patterns which thoroughly reproduce individual, football-related motions.

Objective: To verify the hypothesis concerning the PNF method exerting a favorable influence on selected motor abilities in young football players

Materials and methods: A group of 14- to 15-year-old football players from the SA Zagłębie Sosnowiec Sports Club was involved. Initial measurements were taken after the final stage of the league games. The experimental group had its training programme enriched by selected PNF method techniques. After the completion of the 6-month training programme, the players were subjected to the final series of measurements. By that time, each person in the experimental group had taken part in 30 15-min-long PNF training sessions, which were conducted 2 times a week in the following order: pelvic patterns, trunk patterns, unilateral lower limb patterns, and symmetric reciprocal lower limb patterns. The sequences were executed bilaterally with 6 repetitions each. The total duration of a single PNF session was around $15 \mathrm{~min}$.

Results: The maximal isometric torque produced by the flexor and extensor muscles was enhanced in both groups for both lower extremities; however, a greater in the experimental group. For extension, the difference between the initial and final outcomes accounted for $17.2 \%$ on the right and $16 \%$ on the left side of the body. For flexion, we observed differences of $44.7 \%$ and $35.3 \%$, respectively. In the control group, these differences were considerably smaller. Also, a great im-
\end{abstract}


provement of the kinaesthetic force differentiation ability was noticed in the experimental group. The absolute error for extension was lessened by $75.8 \%$ on the right side and $74.9 \%$ on the left side. Similarly, the absolute error for flexion was decreased: $61.1 \%$ on the right and $57.3 \%$ on the left side. The corresponding values were significantly smaller in the control group. The ability of explosive force differentiation proved to be bet- ter in the experimental group after the six-month training regimen. The absolute error decreased by $52.3 \%$, while in the control group, its reduction was only half as significant (26.5\%).

Conclusions: The kinaesthetic force differentiation ability was improved in the case of the laboratory tests but not in the specific tests. The PNF techniques influenced the level of conditional motor abilities as well.

\section{Introduction}

Nowadays, numerous pursuits aiming to improve the effectiveness of both young and qualified football players are undertaken. Their focus is usually on technique and tactics, leaving the process of shaping the coordination sphere of motor abilities aside. This is especially remarkable in the case of young sportsmen. Football coaches place strong emphasis on all abilities which are directly linked to the effectiveness of sport performance. However, such an approach only fulfils the objective of achieving the highest performance and may actually be unfavourable for young athletes in particular. In the opinion of coaches, young football players frequently seem to be as skilled as experienced players. In practice, however, one may observe that even with a high technical level, junior players still do not possess the ability to harmonize their motion with tactical moves on the field, to alternate their pace of motion, or to perform any other action under the pressure of the opponent. In such circumstances, the coordination abilities of an experienced player represent a factor that promotes greater efficiency. This is the reason why many specialists emphasize the necessity for combining technical training with the development of coordination abilities, especially in professional football [1].

In the literature, as many as 20 or more coordination motor abilities (CMAs) are counted. It is worth noting that a given CMA depends on the specificity of a given sport discipline, the charac- ter of the movements performed, and the parts of the body involved in this motion. Seven CMAs are distinguished in football: adjustment and readjustment of the motor action, kinaesthetic force differentiation, sense of motion rhythm, movement coupling, sense of direction, speed of reaction, and static and dynamic balance. For specialists, both adjustment and readjustment of the motor action and kinaesthetic force differentiation rank among the most relevant $[2,3]$.

The ability of kinaesthetic force differentiation influences precision of movement and its energetic cost. A proper assessment of the data concerning joint position (spatial parameters), muscle tone (force parameters), and velocity of motion (time parameters) lies in its background. A player with this ability can execute movements in any given alignment of the body, with accurate force and in proper time, which defines the main variables of precision of passes, shots on goal, and receptions of the ball [4].

\section{Objective}

A football player's ability to reproduce a given motor task is positively correlated with the lengthening of the training period. Motor skills are clearly linked to the creation of proper motor habits within an individual sport discipline. However, if the training cycle is disturbed in any way (trauma, illness, etc.), which results in an 
extended exclusion from exercise, the player will inevitably suffer from a decreased level of performance after returning to the game. In such circumstances, the pace of regaining neuro-muscular coordination is a crucial factor in returning to effective play. Rebuilding coordination gradually leads to a more precise activation of the muscle groups and control force-movement and time-movement parameters, all of which are necessary for fluent passage from one phase of a given exercise to another. Restored coordination may also lessen the energetic cost of an individual motion pattern.

The complex, central coordination neutral processes are dependent on smaller data-organisation mechanisms which can be found within the control and movement regulation system [3, 4]. The proprioceptive neuromuscular facilitation (PNF) method provides a full range of therapeutic patterns, which thoroughly mimic individual football-related motions. The objective of this study is to verify the hypothesis concerning the PNF method exerting a favourable influence on selected motor abilities in young football players.

\section{Materials and methods}

A total of 21 male football players, aged 14-15 years, from the SA Zagłębie Sosnowiec Sports Club were evaluated (more detailed characteristics of the subjects are presented in Table 1). Only healthy players with no history of trauma or pain ailments during the experimental period qualified for the study. The subjects were randomly divided into two subgroups-experimental and control-which were homogenous as far as age, body mass, and height were concerned (Table 1). In evaluating young players, age-related homogeneity is of particular importance, as many are entering the puberty spurt, in which all stimuli introduced into the training process may influence either the central or peripheral nervous system and, therefore, affect the level of coordination [4]. We informed all subjects about the objective of the study and all experimental procedures. All the participants signed their informed consent and were freely allowed to refuse participation at any stage of the study. The entire protocol was in agreement with the Helsinki Declaration of 1975, as revised in 1983 .

Table 1. Characteristics of the study groups: number $(\mathrm{N})$ and mean values and standard deviations of the age, body mass, and height. The $p$-values of testing the homogeneity of the groups are also presented.

\begin{tabular}{|l|c|c|c|c|c|c|}
\hline \multirow{2}{*}{ Group } & \multirow{2}{*}{$\mathbf{N}$} & \multirow{2}{*}{ Age [years] } & \multicolumn{2}{|c|}{ Body mass [kg] } & \multicolumn{2}{c|}{ Body height [cm] } \\
\cline { 4 - 7 } & & & Initial & Final & Initial & Final \\
\hline Experimental & 11 & $14.68 \pm 0.37$ & $44.43 \pm 7.73$ & $45.74 \pm 7.63$ & $152.82 \pm 9.56$ & $155.0 \pm 8.97$ \\
\hline Control & 11 & $14.82 \pm 0.37$ & $44.0 \pm 4.14$ & $45.28 \pm 4.34$ & $154.18 \pm 5.33$ & $156.9 \pm 5.13$ \\
\hline p-value & & NS & NS & NS & NS \\
\hline
\end{tabular}

Notes: NS - not significant.

All experimental procedures were executed in the afternoon (due to the school schedule) on non-training days or before the training session to minimize the influence of fatigue. The testing protocol was preceded by a versatile, 20-min warm up, which was performed by a physiotherapist in cooperation with a football instructor. Isometric muscle contractions were performed 
and evaluated in the Motor Analysis Laboratory, Katowice. A sport-related testing protocol was performed at the SA Zagłębie Sosnowiec Sports Hall, with medical assessments being executed by an orthopaedist.

Baseline measurements were taken at the conclusion of the league games. During the winter break and spring league session, the experimental group followed a training programme enriched by selected PNF techniques. The subjects in the experimental group were divided into two categories: some of them received their PNF training on Tuesdays and Thursdays, while the others on Wednesdays and Fridays.

After completing the 6-month training programme (May and June of 2005), the players were subjected to the final series of measurements. At the conclusion of the study, the experimental group participated in 30 PNF training sessions, each lasting for $15 \mathrm{~min}$.

The measurements were taken in the following order:

- First, the Enraf Nonius EN-Knee chair was used for measuring the isometric muscle contraction parameters. The subject was properly positioned in the chair with his trunk stabilised by Velcro belts. The tested lower limb was immobilised in a position of $70^{\circ}$ flexion (half of the standard normal range of knee motion), which constituted a self-administered modification with respect to the traditionally used $90^{\circ}$ of flexion for isometric testing. After receiving the signal, the subject performed a maximal isometric contraction of the knee flexors, followed by a maximal contraction of the extensors. An identical procedure was performed on the opposite limb with a short, 2 -min break in between. The whole procedure was repeated 2 min later, but with the modification of subjectively using only half of the force produced previously. No repetitions were possible. A light, 10-min warm up on a stationary bicycle with minimal loading was also performed. The original Enraf Nonius EN-Knee software for Windows was utilised. The absolute values of the following isometric contraction parameters were further measured: (1) the maximal torque for extension [Nm], (2) torque for extension $50 \%$ of maximal force used [Nm], (3) maximal torque for flexion [Nm], and (4) torque for flexion $50 \%$ of maximal force used [Nm].

- Second, a two-legged, open-eyed long jump from a steady position (explosive force test) was performed. The best result of two trials was taken into consideration. The subject assumed a starting position with his toes on a line drawn on the floor and independently decided when to jump. A non-elastic tape served as the measuring device. The results were rounded to the closest $5 \mathrm{~cm}$. The trials were separated by a 1-min break.

- Third, a two-legged, blindfolded long jump was examined. After performing the open-eyed long jump, the subjects were blindfolded to complete the next task, in which they subjectively decided to produce as much force as to reach half of the maximal distance achieved in the open-eyed trial. All other details were as described above. Two trials were performed, and only the best result was recorded. The error in relation to $50 \%$ of the maximal distance was calculated according to the following formula:

|absolute error $\mid=$ maximal result (eyes-open) $50 \%$ of maximal result

- Last, the subjects performed a ball shot to a target. Two concentric squares (side lengths of 2 and $4 \mathrm{~m}$ ) were marked on the floor. A 15-m line was drawn from the centre line. From that line, the subject was asked to shoot a ball (mass $0.7 \mathrm{~kg}$, circumference $70 \mathrm{~cm}$ ) towards the marked square targets. The ball was thrown slightly into the air and then kicked with a straight upper foot. Eight right-legged and eight left-legged shots were performed. The subjects gained 2 points for hitting the internal square and 1 point for hitting the external square. The points were totalled for the right and left lower extremities. 
The statistics were based on the paired Wilcoxon test due to frequent deviations of the empirical distribution of variables from the normal distribution (Kolmogorov-Smirnov test). The critical $\mathrm{p}$-value was set at $\mathrm{p}<0.05$.

For a better illustration of the data, the differences between the results of the initial and final series of measurements were calculated. The following equation for normalization was applied:

$$
Z=\frac{2 \times d_{1-2}}{S_{1}+S_{2}}
$$

$\mathrm{Z}$ - normalised value

$\mathrm{d}_{1-2}$ - difference between the initial and final measurements

$\mathrm{S}_{1}$ - initial standard deviation

$\mathrm{S}_{2}$ - final standard deviation

The following sequence of PNF exercises was applied 2 times a week during a period of 6 months: pelvic patterns, trunk patterns, unilateral lower limb patterns, and symmetric reciprocal lower limb patterns. The patterns were executed bilaterally with 6 repetitions for each side. The total time of a single PNF session was approximately 15 min. A properly trained physiotherapist was responsible for the execution of all PNF exercises. A light 15-min warm up on a stationary bicycle with minimal loading was introduced.

Focusing on football specificity, the following PNF patterns were selected as most useful:

- pelvic patterns: posterior and anterior elevation of the pelvis, posterior and anterior depression of the pelvis for the enhancement of pelvis stability, and motor coordination in relation to a stable trunk and/or lower limbs;

- unilateral patterns: flexion-adduction-external-rotation pattern with knee flexion, extension-abduction-internal-rotation pattern with knee extension for mimicking kicks with the medial aspect of the foot; flexion-abduction-internal-rotation pattern with knee flexion, and extension-adduction-external-rotation pattern with knee extension for mimicking kicks with the lateral aspect of the foot;

- patterns for torso controlled by legs: flexion pattern with flexion of knee joints, extension pattern with extension of knee joints for enhancement of the global synergy and synkinesis between the trunk, pelvis, and lower limbs;

- symmetric reciprocal patterns: lower limbs acting in a common oblique plane; the sagittal-plane movement is opposite for the left and the right extremities as a kind of closed kinetic chain enhancing the opposite movements of the lower limbs.

The PNF methodology maximally activates the nervous system receptors to create the expected goal. Thereby, the following stimulation approaches were incorporated during PNF training:

- optimal load for individual subject;

- elongation of the muscle by appropriate initial position;

- engagement of stretch reflexes: passive stretch of the muscle right before starting the movement;

- appropriate tactile contact: on the skin over activated muscle groups;

- visual control: engagement of the subject's eyes for better stimulation;

- isometric contraction of the active muscles when closing the movement;

- rhythmic initiation of the movement: a brief description of the movements that the subject is up to perform;

- alternating muscle work technique: incorporating concentric, eccentric, and isometric contractions within individual movement;

- technique of stabile turnings: slowly changing isotonic contractions when the load continuously switches between opposite directions. 


\section{Results}

For the kinaesthetic force differentiation ability, there was a degree of homogeneity in the groups, since significant differences between initial and final results were registered in both. However, the final outcome was better in the experimental group, where the selected PNF patterns were introduced (Tables 2 and 3).

An analysis of mistakes made during a trial of kinaesthetic differentiation for both a movement of extension and one of flexion showed essential differences between the control and experimental groups $(\mathrm{p}<0.05)$. An ANOVA test was used to indicate the significance level of these differences. A mixed model of analysis of variance (ANOVA) and post-hoc Tukey's test. The obtained data are shown in Figures 1-4.

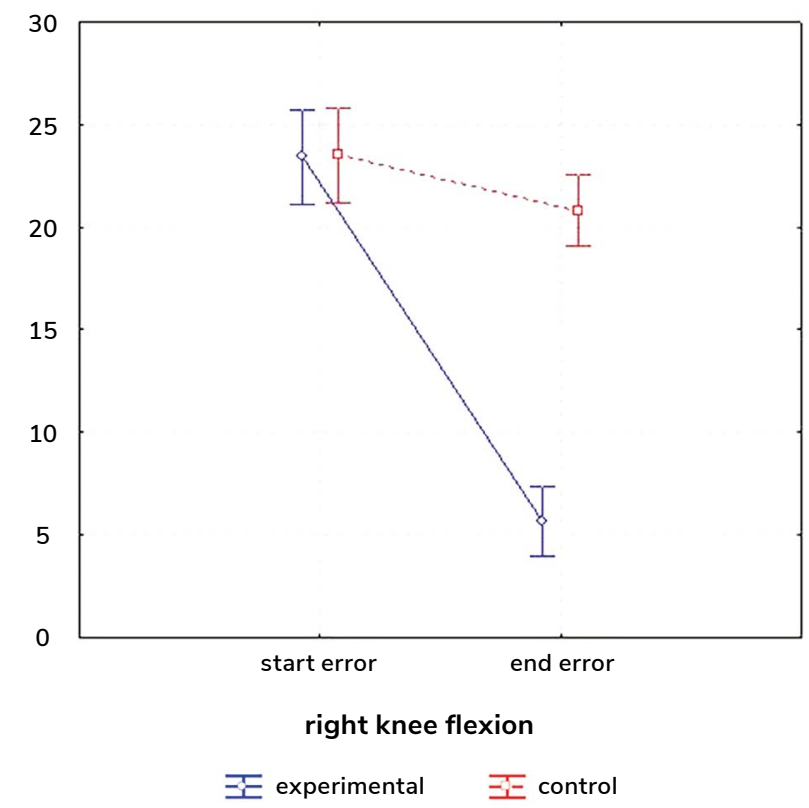

Figure 1. Mistake level measured for right knee straightening $(p<0.001)$.

A post-hoc analysis showed that significant differences occurred between the first and the second measurements $(\mathrm{p}<0.001)$ in both the experimental and the control groups.

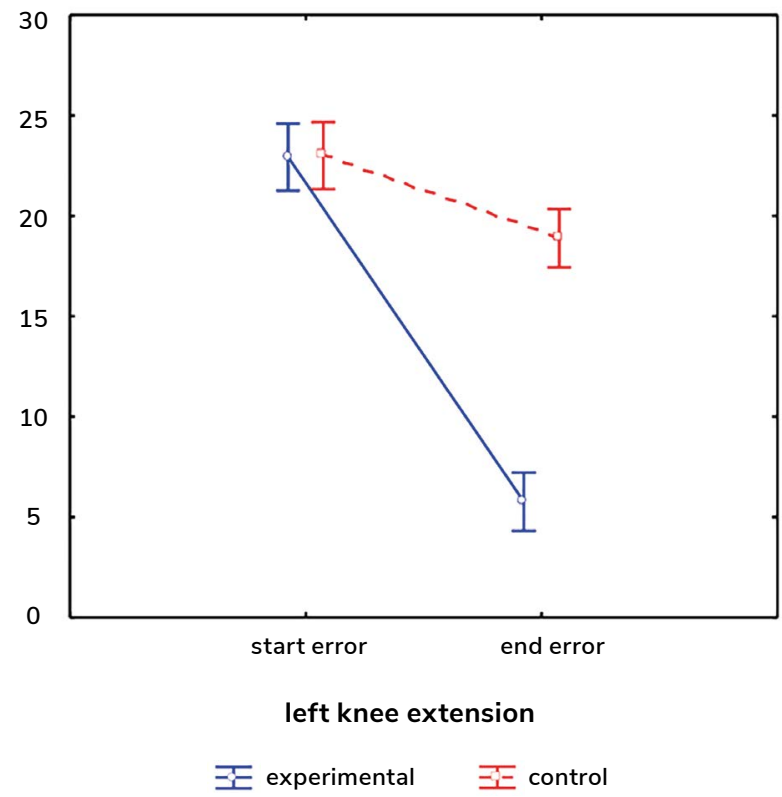

Figure 2. Mistake level measured for left knee straightening $(p<0.001)$.

An analysis using a post-hoc test showed that not only the differences for this movement between the first examination of the control group and that of the experimental one was important. The other differences also showed a statistical importance, with $\mathrm{p}<0.01$ in the control group and $\mathrm{p}<0.001$ in the experimental group.

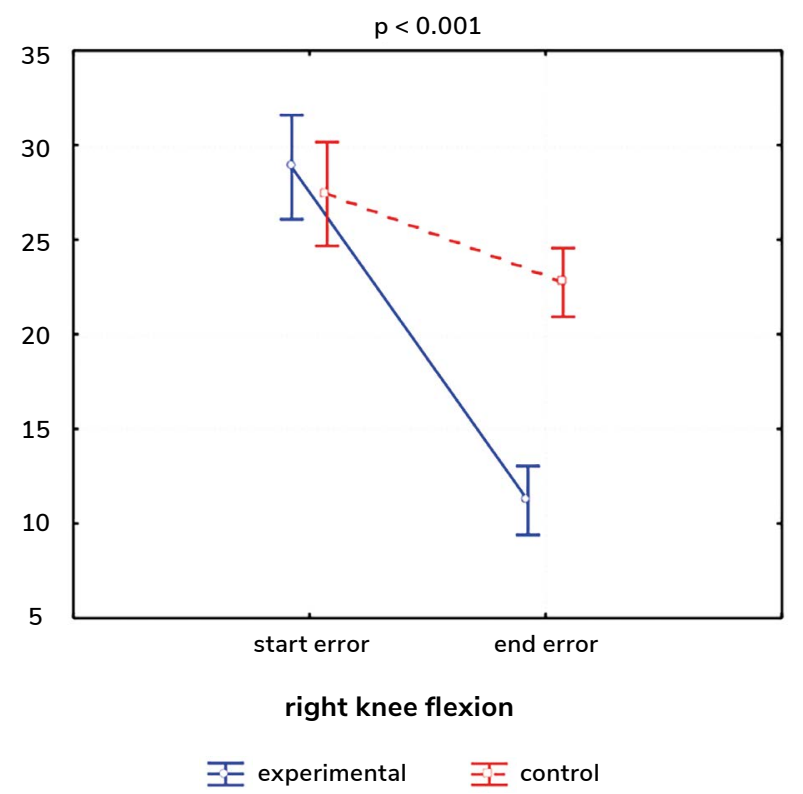

Figure 3. The mistake level measured for left knee extension $(p<0.001)$. 
A post-hoc analysis for this measurement shows that, as for the left knee extension, differences did not occur only in the initial examination. The differences between the first and the last examination were $p<0.001$ in the experimental group, while in the control group, the p-value slightly exceeded 0.05 .

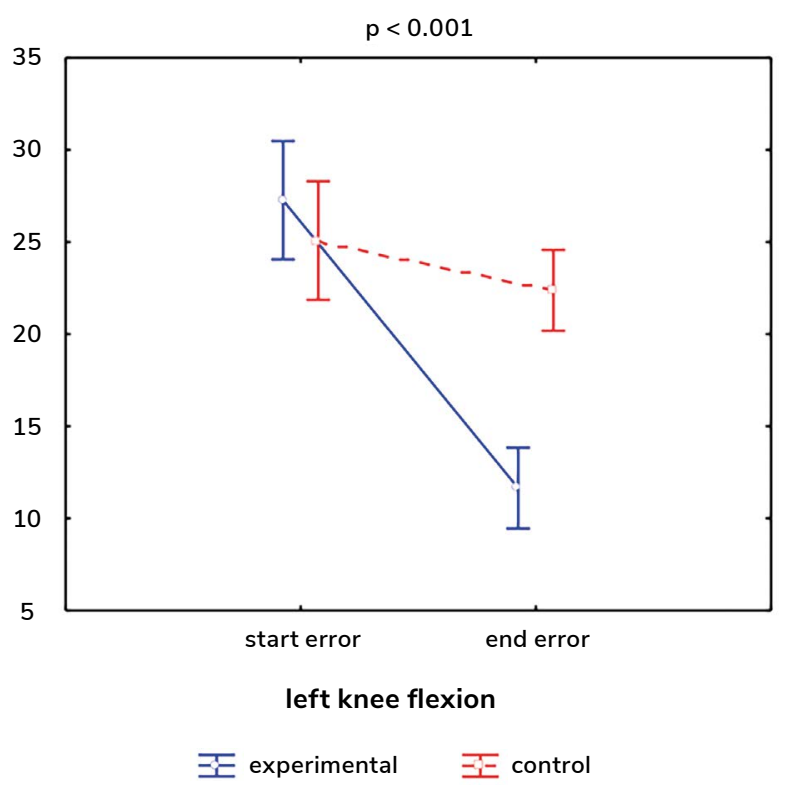

Figure 4. The mistake level measured for left knee extension $(p<0.001)$

Using 'the following measurements' implies that an enumeration of measurements should follow; please specify to which measurements / movements that were measured you are referring in the studied group $(\mathrm{p}<0.001)$.
The maximal isometric torque produced by the flexor and extensor muscles was enhanced in both groups for both lower extremities (Tables 2 and 3 ). Normalized values were used to depict these changes in Figures 5 and 6 . The increased torque values were also greater in the experimental group. For extension, the difference between the initial and final outcomes accounted for $17.2 \%$ on the right side and $16 \%$ on the left side of the body. For flexion, we observed differences of $44.7 \%$ and $35.3 \%$, respectively. In the control group, these differences were considerably smaller: for extension, $8.3 \%$ on the right and $11.6 \%$ on the left; for flexion, $18.7 \%$ on the right side and $14 \%$ on the left side of the body (Tables 2 and 3).

Most importantly, a great improvement of the kinaesthetic force differentiation ability was noticed in the experimental group. The absolute error for extension was lessened by $75.8 \%$ on the right side and $74.9 \%$ on the left side of the body. Similarly, the absolute error for flexion was decreased: $61.1 \%$ on the right side and $57.3 \%$ on the left side (Tables 2 and 3). The corresponding values were significantly smaller in the control group: $11.5 \%, 14.1 \%, 17.1 \%$, and $10.8 \%$, respectively.

The ability of explosive force differentiation proved to be better in the experimental group after the six-month training regimen (Table 4). The absolute error decreased by $52.3 \%$, while in the control group, its reduction was only half as significant (26.5\%) (Figure 7).

Table 2. Mean values, standard deviations, and p-levels (Wilcoxon test) for isometric torques (knee extension/flexion max.) and kinaesthetic force differentiation ability (knee extension/flexion 50\%, 50\% extension/flexion absolute error) in the experimental group.

\begin{tabular}{|c|c|c|c|c|c|c|}
\hline \multirow{2}{*}{ Parameter } & \multicolumn{2}{|c|}{ Right } & \multirow{2}{*}{ p-value } & \multicolumn{2}{|c|}{ Left } & \multirow{2}{*}{ p-value } \\
\cline { 2 - 3 } \cline { 5 - 6 } & Initial & Final & & Initial & Final & \\
\hline \multirow{2}{*}{ Knee extension max $[\mathrm{Nm}]$} & 165.73 & 194.27 & $<0.01$ & 175.0 & 203.09 & $<0.01$ \\
& \pm 14.27 & \pm 16.16 & & \pm 16.17 & \pm 16.97 & \\
\hline \multirow{2}{*}{ Knee extension 50\% $[\mathrm{Nm}]$} & 121.55 & 107.97 & $<0.01$ & 127.64 & 113.0 & $<0.01$ \\
& \pm 10.45 & \pm 7.75 & & \pm 12.86 & \pm 6.99 & \\
\hline
\end{tabular}




\begin{tabular}{|l|l|l|l|l|l|l|}
\hline 50\% extension absolute error [\%] & $\begin{array}{l}44.18 \\
\pm 8.30\end{array}$ & $\begin{array}{l}86.3 \\
\pm 10\end{array}$ & $<0.01$ & $\begin{array}{l}47.36 \\
\pm 6.17\end{array}$ & $\begin{array}{l}90.09 \\
\pm 11.21\end{array}$ & $<0.01$ \\
\hline Knee flexion max [Nm] & $\begin{array}{l}95.94 \\
\pm 16.63\end{array}$ & $\begin{array}{l}135.91 \\
\pm 19.37\end{array}$ & $<0.01$ & $\begin{array}{l}101.55 \\
\pm 16.89\end{array}$ & $\begin{array}{l}137.36 \\
\pm 17.59\end{array}$ & $<0.01$ \\
\hline Knee flexion 50\% [Nm] & $\begin{array}{l}75.36 \\
\pm 11.93\end{array}$ & $\begin{array}{l}82.87 \\
\pm 9.59\end{array}$ & $<0.05$ & $\begin{array}{l}77.96 \\
\pm 11.21\end{array}$ & $\begin{array}{l}84.62 \\
\pm 10.78\end{array}$ & $<0.05$ \\
\hline 50\% flexion absolute error [\%] & $\begin{array}{l}20.67 \\
\pm 6.09\end{array}$ & $\begin{array}{l}53.04 \\
\pm 10.41\end{array}$ & $<0.01$ & $\begin{array}{l}23.58 \\
\pm 7.59\end{array}$ & $\begin{array}{l}52.74 \\
\pm 7.47\end{array}$ & $<0.01$ \\
\hline
\end{tabular}

Table 3. Mean values, standard deviations, and p-levels (Wilcoxon test) for isometric torques (knee extension/flexion max.) and kinaesthetic force differentiation ability (knee extension/flexion 50\%, 50\% extension/flexion absolute error) in the control group.

\begin{tabular}{|c|c|c|c|c|c|c|}
\hline \multirow{2}{*}{ Parameter } & \multicolumn{2}{|c|}{ Right } & p-value & \multicolumn{2}{c|}{ Left } & p-value \\
\cline { 2 - 7 } & Initial & Final & & Initial & Final & \\
\hline \multirow{2}{*}{ Knee extension max [Nm] } & $\begin{array}{l}164.64 \\
\pm 9.03\end{array}$ & $\begin{array}{l}178.27 \\
\pm 9.55\end{array}$ & $<0.01$ & $\begin{array}{l}172.18 \\
\pm 18.66\end{array}$ & $\begin{array}{l}192.09 \\
\pm 17.73\end{array}$ & $<0.01$ \\
\hline \multirow{2}{*}{ Knee extension 50\% [Nm] } & $\begin{array}{l}121.09 \\
\pm 9.66\end{array}$ & $\begin{array}{l}126.18 \\
\pm 7.67\end{array}$ & $<0.05$ & $\begin{array}{l}125.64 \\
\pm 13.91\end{array}$ & $\begin{array}{l}132.36 \\
\pm 13.49\end{array}$ & NS \\
\hline \multirow{2}{*}{$50 \%$ extension absolute error [\%] } & $\begin{array}{l}43.54 \\
\pm 6.04\end{array}$ & $\begin{array}{l}52.09 \\
\pm 6.73\end{array}$ & $<0.05$ & $\begin{array}{l}46.54 \\
\pm 7.03\end{array}$ & $\begin{array}{l}59.73 \\
\pm 6.91\end{array}$ & $<0.01$ \\
\hline Knee flexion max [Nm] & $\begin{array}{l}95.73 \\
\pm 12.35\end{array}$ & $\begin{array}{l}113.6 \\
\pm 11.62\end{array}$ & $<0.01$ & $\begin{array}{l}98.38 \\
\pm 22.43\end{array}$ & $\begin{array}{l}112.15 \\
\pm 22.14\end{array}$ & $<0.01$ \\
\hline Knee flexion 50\% [Nm] & $\begin{array}{l}73.86 \\
\pm 8.49\end{array}$ & $\begin{array}{l}82.6 \\
\pm 8.8\end{array}$ & $<0.01$ & $\begin{array}{l}73.15 \\
\pm 14.0\end{array}$ & $\begin{array}{l}80.49 \\
\pm 12.72\end{array}$ & $<0.01$ \\
\hline \multirow{2}{*}{$50 \%$ flexion absolute error [\%] } & $\begin{array}{l}21.86 \\
\pm 5.96\end{array}$ & $\begin{array}{l}31.01 \\
\pm 5.14\end{array}$ & NS & $\begin{array}{l}25.24 \\
\pm 9.2\end{array}$ & $\begin{array}{l}31.66 \\
\pm 10.59\end{array}$ & NS \\
\hline
\end{tabular}

Notes: NS - not significant. 


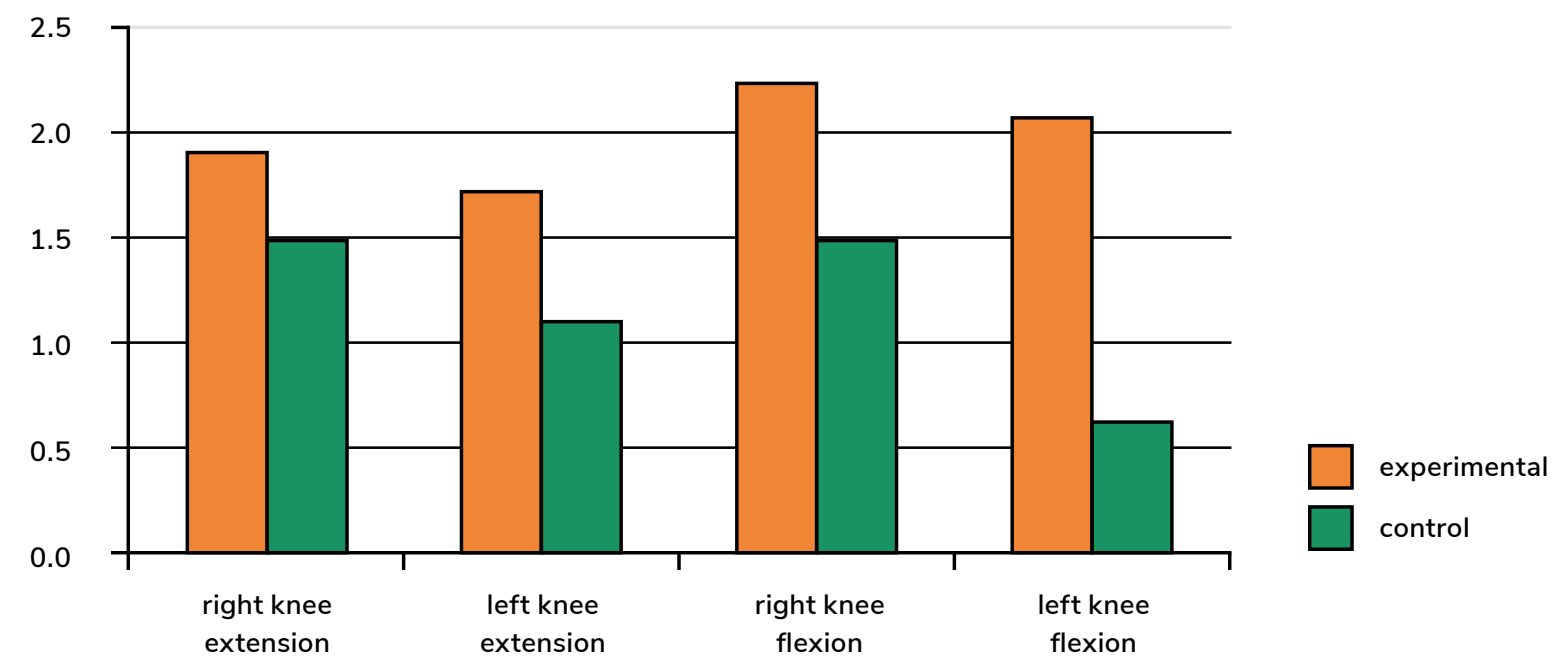

Figure 5. Normalized values of differences between the initial and final isometric torques in the experimental and control groups.

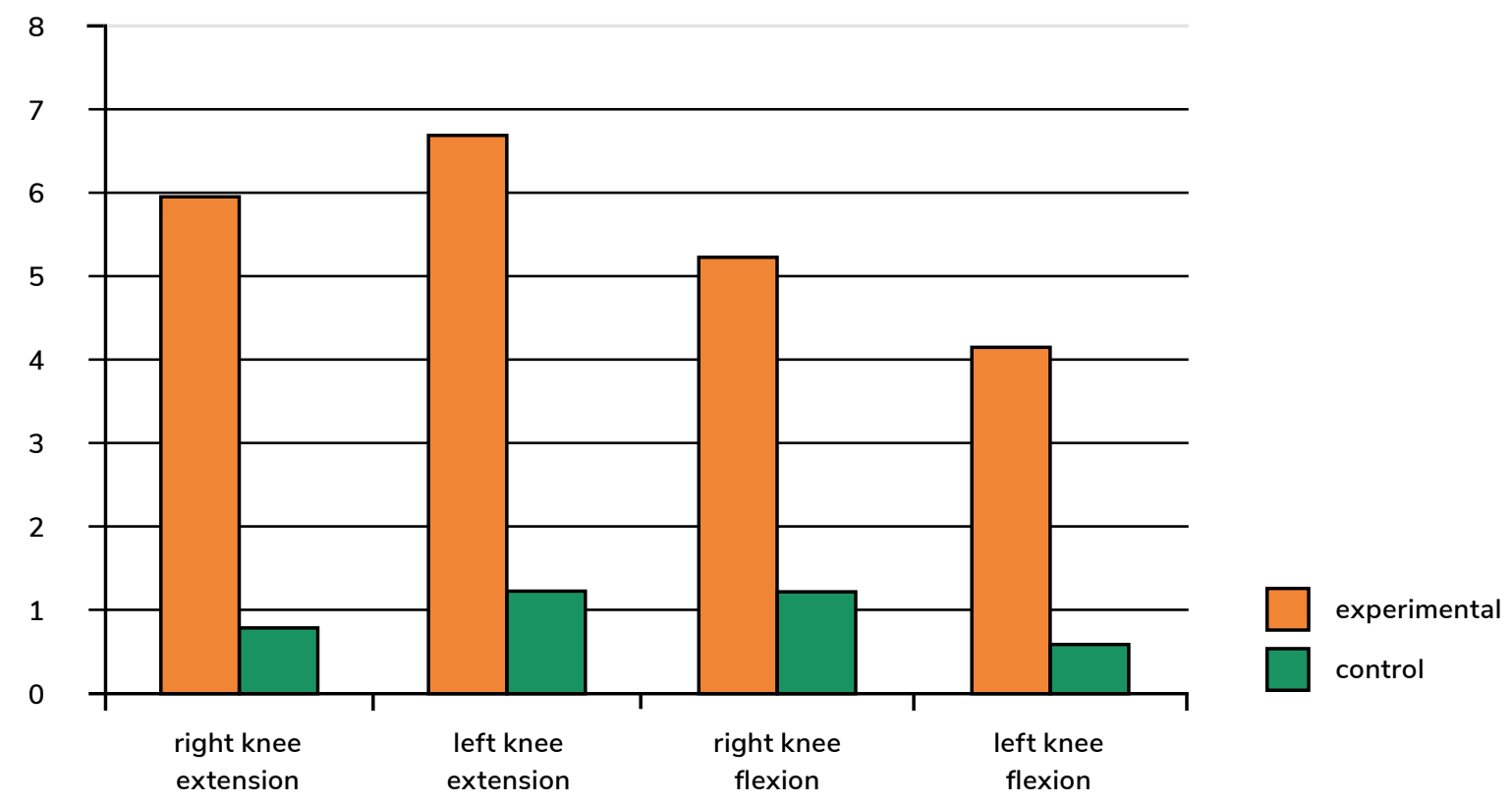

Figure 6. Normalized values of differences between the initial and final absolute errors for force differentiation ability in the experimental and control groups. 
Table 4. Mean values, standard deviations, and p-levels (Wilcoxon test) for explosive force (long jump) and explosive force differentiation ability (blindfolded long jump, absolute error) in the experimental and control groups.

\begin{tabular}{|c|c|c|c|c|c|c|}
\hline \multirow{2}{*}{ Test } & \multicolumn{2}{|c|}{ Experimental } & p-value & \multicolumn{2}{c|}{ Control } & p-value \\
\cline { 2 - 7 } & Initial & Final & & Initial & Final & \\
\hline Long jump[cm] & $\begin{array}{l}184.09 \pm \\
13.0\end{array}$ & $\begin{array}{l}201.36 \\
\pm 12.47\end{array}$ & $<0.01$ & $\begin{array}{l}179.55 \\
\pm 16.65\end{array}$ & $\begin{array}{l}185.91 \pm \\
15.14\end{array}$ & $<0.01$ \\
\hline Blindfolded long jump [cm] & $\begin{array}{l}104.09 \\
\pm 10.91\end{array}$ & $\begin{array}{l}100.0 \\
\pm 12.04\end{array}$ & NS & $\begin{array}{l}98.64 \\
\pm 18.59\end{array}$ & $\begin{array}{l}100.46 \\
\pm 12.14\end{array}$ & NS \\
\hline \multirow{2}{*}{ Blindfolded jump absolute error [\%] } & $\begin{array}{l}9.28 \\
\pm 2.44\end{array}$ & $\begin{array}{l}4.43 \\
\pm 2.01\end{array}$ & $<0.01$ & $\begin{array}{l}10.3 \\
\pm 3.03\end{array}$ & $\begin{array}{l}7.57 \\
\pm 2.63\end{array}$ & $<0.01$ \\
\hline
\end{tabular}

Notes: NS - not significant.

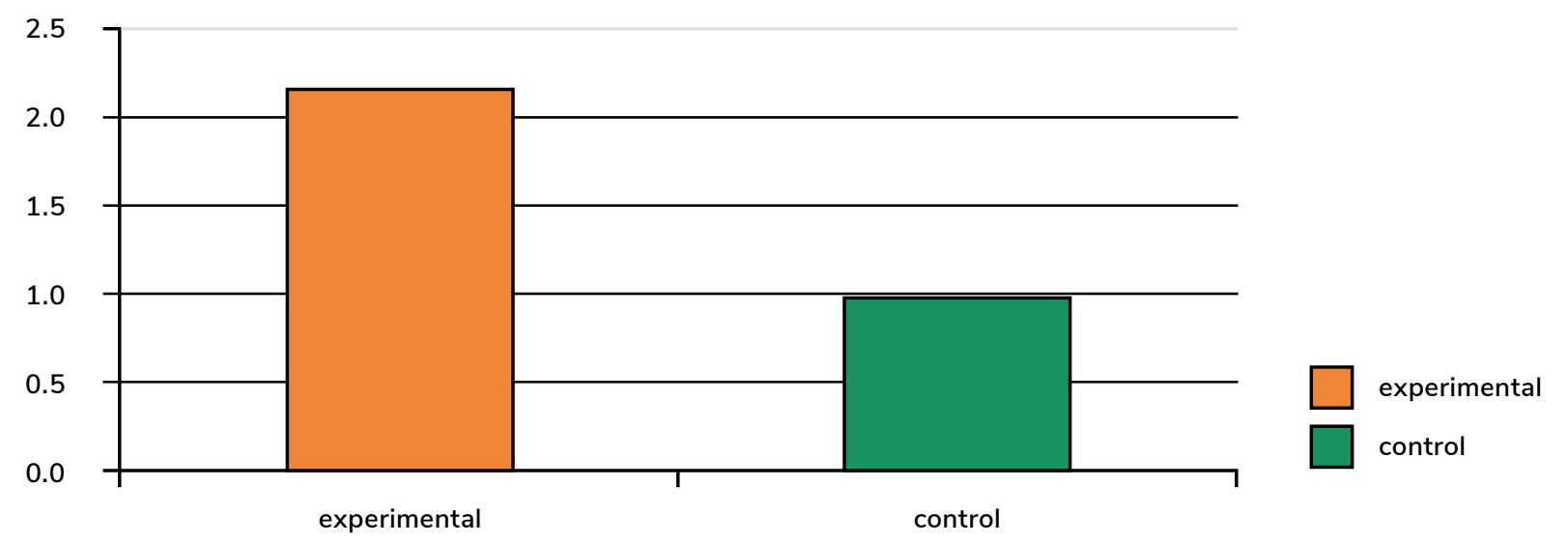

Figure 7. Normalized values of differences between the initial and final values of absolute errors for explosive force differentiation ability in the experimental and control groups.

There were no significant intra-group differences in the functional evaluation of the force differentiation ability (ball shot to a target) in either the total score or in the number of direct hits (Tables 5 and 6 ).

Table 5. Mean values, standard deviations, and p-levels (Wilcoxon test) for the functional evaluation (ball shot to a target) of kinaesthetic force differentiation ability (the total score and number of direct hits) in the experimental group.

\begin{tabular}{|c|c|c|c|c|c|c|}
\hline \multirow{2}{*}{ Parameter } & \multicolumn{2}{|c|}{ Right } & \multirow{2}{*}{ p-value } & \multicolumn{3}{|c|}{ Left } \\
\cline { 2 - 3 } & Initial & Final & Initial & Final & p-value \\
\hline \multirow{2}{*}{ Total score } & $\begin{array}{l}5.45 \\
\pm 2.11\end{array}$ & $\begin{array}{l}5.27 \\
\pm 1.42\end{array}$ & NS & $\begin{array}{l}4.45 \\
\pm 2.3\end{array}$ & $\begin{array}{l}5.0 \\
\pm 1.79\end{array}$ & NS \\
\hline Direct hits & $\begin{array}{l}4.18 \\
\pm 1.47\end{array}$ & $\begin{array}{l}4.0 \\
\pm 1.1\end{array}$ & NS & $\begin{array}{l}3.27 \\
\pm 1.79\end{array}$ & $\begin{array}{l}4.0 \\
\pm 1.18\end{array}$ & NS \\
\hline
\end{tabular}

Notes: NS - not significant. 
Table 6. Mean values, standard deviations, and p-levels (Wilcoxon test) for the functional evaluation (ball shot to a target) of kinaesthetic force differentiation ability (the total score and number of direct hits) in the control group.

\begin{tabular}{|c|c|c|c|c|c|c|}
\hline \multirow{2}{*}{ Parameter } & \multicolumn{2}{|c|}{ Right } & \multirow{2}{*}{$\mathrm{p}$-value } & \multicolumn{2}{|c|}{ Left } & \multirow{2}{*}{$\mathrm{p}$-value } \\
\hline & Initial & Final & & Initial & Final & \\
\hline Total score & $\begin{array}{l}5.36 \\
\pm 1.8\end{array}$ & $\begin{array}{l}5.36 \\
\pm 1.93\end{array}$ & NS & $\begin{array}{l}4.55 \\
\pm 2.16\end{array}$ & $\begin{array}{l}5.18 \\
\pm 0.98\end{array}$ & NS \\
\hline Direct hits & $\begin{array}{l}4.27 \\
\pm 1.79\end{array}$ & $\begin{array}{l}4.09 \\
\pm 1.14\end{array}$ & NS & $\begin{array}{r}3.36 \\
\pm 1.5\end{array}$ & $\begin{array}{l}3.73 \\
\pm 0.79\end{array}$ & NS \\
\hline
\end{tabular}

Notes: NS - not significant.

\section{Discussion}

A review of the literature depicts two specialized approaches to evaluating the CMAs in football, although they may translate to other sport disciplines as well. The first approach is based on the assumption that, in the field of football, coordination abilities should always be assessed by means of specific tests, which should always be "with the ball' [5]. The second approach, supported by Mynarski and Zywicka [6] and Raczek [7], incorporates non-specific, laboratory tests which give an overall view of the given coordination ability. This style of testing has revealed significant differences between young football players whose training was enriched by selected PNF patterns and players who only exercised regularly.

In particular, this study aimed to verify the hypothesis that PNF techniques constitute one of the factors that influence specific coordination football abilities. Therefore, the outcomes of the specific tests were the most challenging to interpret. Both groups showed similar, but usually non-significant, increases of the functional kinaesthetic force differentiation ability, which indicates only a slight influence from the PNF training. However, it seems unusual that regular football training did not affect them. It is likely that all subjects had already achieved the optimal level of specific coordination abilities. All subjects had trained for several years (from 2 to 7 years). To better understand this issue, research incorporating PNF techniques must be conducted on young players who are just starting the training process. Only then can we establish if an improved force differentiation ability, as indicated by non-specific laboratory tests, can also be noticed in the changing level of specific football skills.

It is impossible to exclude the possibility that small increases in the CMAs, as shown by specific tests, are the result of improper training loads. As described by some researchers [7], it may be the case that in Poland, coordination abilities are treated as secondary and are rarely shaped in an isolated, specific fashion.

A different picture can be observed in the outcomes of the laboratory tests. The kinaesthetic force differentiation ability showed a significantly larger increase in the experimental group than in the control group. Therefore, the hypothesis of PNF patterns influencing this ability appears to find empirical support. However, according to Starosta [8], it is based on adroit ball handling ('sense of the ball'), and its objective assessment should be performed in exactly the same way. In the future, studies verifying the influence of PNF techniques on the level of football skills should be based on tests developed in accordance to that statement.

\section{Conclusions}

Selected PNF techniques introduced into football training influence the kinaesthetic force diffe- 
rentiation ability, although this result was apparent only in laboratory tests but not in specific tests. PNF exercises affect the level of conditional abilities as well. Having in mind the specificity of the introduced training, this was probably the effect of a greater capability to activate muscle motor units. Selected PNF patterns may constitute an additional, valuable training tool after injuries and contusions, as a quick return to the game depends, among others, on the reduction of coordination deficit. Therefore, the introduction of PNF techniques into the regular training regimen of young football players may be advantageous, since it promotes the development of certain motor abilities.

\section{References}

1. Slimani M, Bragazzi NL, Tod D, Dellal A, Hue O, Cheour F et al. Do cognitive training strategies improve motor and positive psychological skills development in soccer players? Insights from a systematic review. J Sports Sci. 2016; 34 (24): 2338-2349.

2. Rommers N, Mostaert M, Goossens L, Vaeyens R, Witvrouw E, Lenoir $\mathrm{M}$ et al. Age and maturity related differences in motor coordination among male elite youth soccer players. J Sports Sci. 2019; 37 (2): 196-203.

3. Vänttinen T, Blomqvist M, Häkkinen K. Development of body composition, hormone profile, physical fitness, general perceptual motor skills, soccer skills and on-the-ball performance in soccer-specific laboratory test among adolescent soccer players. J Sports Sci Med. 2010; 9 (4): 547-556.

4. Ridderinkhof KR, Brass M. How Kinesthetic Motor Imagery works: a predictive-processing theory of visualization in sports and motor expertise. J Physiol Paris. 2015; 109 (1-3): 53-63.
5. Vestberg T, Gustafson R, Maurex L, Ingvar M, Petrovic $P$. Executive functions predict the success of top-soccer players. PLoS One. 2012; 7 (4): e34731.

6. Mynarski W, Żywiecka A. Empiryczny model koordynacyjnych uwarunkowań motoryczności człowieka. Katowice, Wydawnictwo AWF, 2004.

7. Raczek J. Rozwój-podstawowy cel i wyznacznik szkolenia sportowego dzieci i młodzieży (wybrane aspekty). Sport Wycz. 2001 9-10, 40-69.

8. Starosta W. Motoryczne zdolności koordynacyjne: znaczenie, struktura, uwarunkowania, kształtowanie. Międzynarodowe Stowarzyszenie Motoryki Sportowej, Warszawa 2003. 